\title{
Editorial
}

\section{Research: Value, Methods, and Publishing}

Notwithstanding the debate about theincreased/decreased quantity of current research activities regarding academic libraries, no one is arguing against the enormous need and opportunity for more research in this area. The growing use of technology in academic libraries, for example, has presented an oasisfor both basic and applied research. The library world is in ferment. It is changing constantly because of the discovery of new ways of doing things. Research is not an academic library banality. Rather, it is a vital and dynamic force that is indispensable to all types of libraries. Research has one prime goal: discovery. If there is no discovery, there is no research. Some research in library and information science is similar to trying to knock down an open door.

\section{Benefits of Research}

During the past winter term, I taught a research methodsclass in Fort Lauderdalefor theUniversity of South Florida's School of Library and Information Science. At the beginning of the class, several students expressed apprehensiveness about its difficulty. Ronald R. Powell's Basic Research Methods for Librarians was the textbook for theclass.1Asthestudentswereintroduced to the various research methodologies, different types of research, data collection techniques, and ways of interpreting and presenting research results, they became more interested in the value of research. Indeed, some actually became excited about the topic.

Without basic research, academic libraries will not solve their problems in a reliable, systematic, and thoughtful manner. The practice of academic librarianship must havea theoretical base. Academic librarians who understand the basic principles of research will be better able to assist students and faculty in their research endeavors. The researcher will quickly becomeaware of a librarian's lack of understanding of basic research methods. Librarians who seek tenure and promotion must havea solid comprehension of research methods in order to perform research and to get results published. It is a sad commentary to learn that an academic librarian has lost employment due to the lack of published research articles. One wonders if the reason was that the librarian did not understand how to conduct research. If one has not had the opportunity to take a research methods class, I recommend reading Powell's book.

\section{An Editor's Observations}

As editor of College \& Research Libraries, I read all the manuscripts submitted for consideration. This is one of the many benefits of the position. Many of the manuscripts that are not published by $C \& R L$ are excellent pieces but for onereason or another are not recommended by the reviewers to be included in the journal. $C \& R L$ is a research journal, and the manuscripts submitted to it undergo rigorous review; about 38 percent of them are accepted for publication. I have been able to help some authors whose manuscripts were rejected to get their work published in other reputable journals.

In my roleas editor of thejournal, I have observed that some authors forget to includea "statement of the problem" in their manuscript, or write one that is unacceptable. The problem statement is the axial center around which the entire research effortturns. The situation isquitesimpleno problem, no research! The problem 
statement must bewritten in completesentences and must be lucid, precise, and stated responsibly. If necessary, subproblems should be used to strengthen the problem statement, but they should not result in more than the totality of the main problem.

Few manuscripts received for $C \& R L ' s$ consideration contain hypotheses. In lieu of hypotheses, research questions are be ing identified and used to guide the research. While developing the research study, various characteristics must be kept in mind. For example, can the study be generalized and used in other library settings? Will its findings/conclusions be compatiblewith existing knowledge? Can the hypotheses/research questions be tested? Reviewers of $C \& R L$ manuscripts use these questions and others when determining the fate of manuscripts.

As Gregory Crawford notes in his article included in this issue, the survey is the most common type of data collection technique used in C\&RL articles. The mailed questionnaire has many advantages (anonymity, frank answers, large number of respondents, easy to administer); its disadvantages includeeliminating personal contact, getting a biased sample due to tendency of highly opinionated people being more likely to respond to questionnaires, and some people disliking mail questionnaires. As academic librarians engage in more qualitative re search, we will begin seeing more focus group interviews used as the primary data-collecting technique.

Based on the manuscripts I have read, prospectiveauthors should giveattention to three obvious areas. First, many of the research manuscripts received fail to ana- lyze and interpret the data collected. It would appear that someauthors "run out of gas" at the end of their manuscripts. Second, many manuscripts do not include a conclusion, which leaves the readers hanging. Convincing and compelling are descriptors of a good conclusion. Third, even though the January issue of $C \& R L$ carries an "Instructions for Authors" section, it is apparent that some authors do not read it. For example, stylistic features do not follow TheChicago M anual of Style, 14th ed. (the style manual followed by $C \& R L)$. And it is obvious that authors do not examine past issues of $C \& R L$ for stylistic features. The lack of conformance to $C \& R L$ stylistic features will not prevent a manuscript from being published in the journal, but prospective authorsshould be cognizant that this type of work will have to be done sooner or later. Also, the lack of or incomplete bibliographic information in the "Notes" section is far too common.

\section{Conclusion}

Due to their increasing work pressures, many academic librarians believe they have less time for research and reflection and for publishing the findings of research. And thisphenomenon is occurring concurrently at a critical time in our civilization when we need to grasp a better understanding of why we do what wedo. We cannot bask in a fog of indecision and procrastination. Much of our future will depend on how well we analyze/resolve problems dispassionately and usethescientific method to promote self-assurance and reduce panic during constant change and greater ambiguity. Research powers improvement in the library world!

DONALDE. RIGGS

Editor

\section{Note}

1. Ronald R. Powell, Basic Reseerch Methods for Librarians, 3rd ed. (Greenwich, Conn.: Ablex, 1997). 